\title{
Low cost diagnostics system dedicated to rolling bearings
}

\author{
Robert Kostek ${ }^{1}$, Janusz Musial ${ }^{2}$, Tomasz Kalaczyński ${ }^{3}$, Marcin Lukasiewicz ${ }^{4}$ \\ University of Science and Technology, Bydgoszcz, Poland \\ ${ }^{1}$ Corresponding author \\ E-mail: ${ }^{1}$ robertkostek@o2.pl, ${ }^{2}$ jamusual@utp.edu.pl, ${ }^{3}$ kalaczynskit@utp.edu.pl, ${ }^{4}$ mlukas@utp.edu.pl
}

Received 1 August 2017; accepted 27 August 2017

DOI https://doi.org/10.21595/vp.2017.18933

Check for updates

\begin{abstract}
This article presents low cost diagnostic system, dedicated to rolling bearings. This system can be widely used in existing machines, to improve their reliability and reduce the costs of maintenance. Low cost electronics sensors, a few microchips, a multi-meter and a programmable micro-controller, which can send data to a computer, were selected. A computer is not necessary in this system, because data can be directly presented on LCD displays; moreover, alarm levers can be signaled with flashing lights and buzzers. This shows that an operational system can be produced with low cost, which is not obvious for managers and mechanical engineers.
\end{abstract}

Keywords: ball-bearing, machinery diagnostics, Arduino.

\section{Introduction}

Rolling bearings are key elements in many machines, and influence their reliability and precision, thus their diagnostics is an important issue. Vibrations of rolling bearings were studied experimentally and simulated by many. Cemplel presented the most important information about vibro-diagnostic, which is still valid [1]. Vibrations of rolling bearing were simulated, which provides an opportunity to select failure modes [2]. Next, degradation of rolling bearing was studied experimentally [3], amplitudes of vibrations and amplitudes of characteristic frequencies were indicated as good state indicators, whereas temperature was almost constant. Signal processing applied in machinery diagnostic was presented in [4], authors presented several useful methods. Moreover, acoustics signal was applied in bearing diagnostics [5]. Temperature of bearing was studied in [6], authors found, that temperature rises with increasing rotary speed, loading force, and roughness. Time histories of temperature were studied in [7]. Authors obtained noisy data, which should be processed to obtain a state indicator. In article [8] authors reported temperature of bearing being greater $105^{\circ} \mathrm{C}$ above ambient temperature and studied temperature distribution around bearing.

Commercial systems dedicated to vibro-diagnostics are expensive, and cost about $\$ 7,500$ [9]. This lead to the conclusion that machinery diagnostics are too expensive for small companies. Nevertheless, there are electronic sensors, which are not expensive, and can be effectively used in machinery diagnostics. This knowledge is not wide-spread among managers and mechanical engineers; thus this issue is described in this article.

Typical failure modes of bearings are: larger amplitude of vibration, louder noise and higher temperature. These phenomena can be measured with an accelerometer, microphone and thermometer. Defects of rolling elements and races result in a larger amplitude of vibration and louder noise. Moreover, FFT (fast Fourier transform) can be used to indicate the kind of defected element. Larger friction torque results in a higher temperature of bearings, which can be measured with temperature sensors. Usually large amplitude of vibration and noise appear before a high temperature. Relations between defects and failure modes tend to be more complex then above-presented, but it describes briefly some idea of the diagnostic system. 


\section{Diagnostic system}

Power dissipated within a bearing determines its temperature, and temperature rises almost proportionally to dissipated power. This power is described by the following formula:

$P_{d}=M_{f} \omega$,

where: $P_{d}$ is dissipated power $\mathrm{W}, M_{f}$ represents friction torque $\mathrm{Nm}$, and $\omega$ denotes rotational speed of shaft $\mathrm{rad} / \mathrm{s}$. Friction torque is difficult to measure, but speed of shaft can be easily measured with Hall effect sensor e.g. A3144, which costs $\$ 0.10$ (Fig. 1(a)) [10]. A magnet fixed to the rotating shaft shifts output states of sensor between high and low. Time instances, which correspond to these changes, are registered, which finally provides an opportunity to calculate the rotational speed. Rotational speed measurement is necessary because of its influences on the temperature of bearings. Pseudo-code 1 presents calculation of rotational speed.

Moreover, two temperature sensors should be used. The first should measure the temperature of air (ambient temperature), and the second, the temperature of the bearing. Then the difference between these two temperatures should be analysed. Alarm levers can be based on bearing temperature and the differences between these two temperatures. The temperature can be measured with an analogue temperature sensor e.g. TMP36GT9Z, which costs \$0.50 (Fig. 1(b)) [6]. This sensor generates an analogue voltage signal, which is directly proportional to the temperature. This provides an opportunity to measure temperature with a multi-meter or Arduino. Temperature is calculated from the following equation:

$T=\frac{U-500}{10}$,

where: $T$ is temperature ${ }^{\circ} \mathrm{C}$ and $U$ is voltage $\mathrm{mV}$. This shows that temperature measurement is not expensive and difficult. Pseudo-code 1 presents calculation of temperature.

Next acceleration can be measured with triple axis MEMS (micro-electro-mechanical system) accelero-meter ADXL335, which costs $\$ 1.80$ (Fig. 1(c)) [10]. Its sensitivity is $300 \mathrm{mV} / \mathrm{g}$ and bandwidth is $0-1.6 \mathrm{kHz}$. This sensor is an example of a low-cost sensor. Its characteristic is described with a linear function:

$a=\frac{U-1500}{300}$,

where: $a$ is acceleration $\mathrm{g}$ and $U$ is voltage $\mathrm{mV}$. Analogue signals can be measured with a multi-meter (RMS - root mean square), or with a micro-controller and then analysed (see Pseudocode 1, Appendix). A very similar solution can be applied for a moving coil microphone. A moving coil microphone generates analogue voltage signals as well, which can be easily processed. Thus, this solution is also not expensive. Summarising this, temperature, amplitude of vibration and acoustic pressure can be state indicators.

(a)

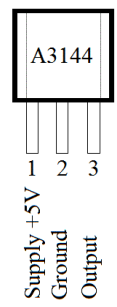

(b)

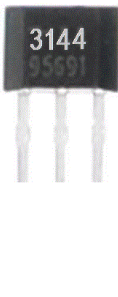

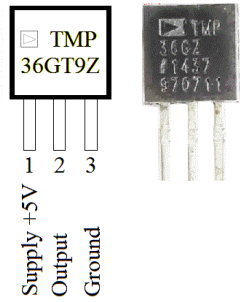

(c)

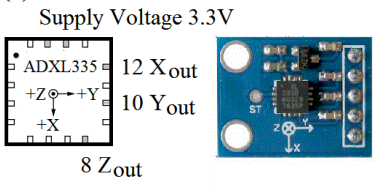

Fig. 1. Selected sensors: a) Hall effect sensor, b) temperature sensor, c) accelero-meter [10] 
The afore-mentioned sensors can be connected to Arduino Uno, which is a micro-controller board based on the ATmega328P. An Arduino possess digital and analogy inputs pins, which can be connected to sensors (Fig. 2). To digital pin 2 a Hall Effect sensor is connected, thus two states are recognised - high and low. Time of shifting is measured in $\mu \mathrm{s}$, which provides an opportunity to calculate rotational speed. Two analogue pins, which are A1 and A2, are connected to temperature sensors. An analogue to digital converter recognises $1024=2^{10}$ states and measures 10000 samples per second; then the voltage and temperature are calculated. A3144 and TMP36GT9Z are supplied from a 5V pin, which simplifies the scheme. Finally pins A3, A4 and A5 are used to measure acceleration. First, the voltage is calculated and then acceleration. This algorithm can be simplified to reduce time of computation. ADXL335 is supplied from $3 \mathrm{~V} 3$ pin. The Arduino Uno costs $\$ 3.30$ [10]. Which gives the total cost of this system near to $\$ 10$.

The ATmega328P is a programmable micro-controller, thus a program should be written to define its function and tasks. First, the variables are defined. Next, the task of any digital pin is defined, and its state is read. Then, instructions in a closed loop are performed. The time of a single revolution is measured, which provides an opportunity to calculate the rotational speed. Then temperatures of air and the bearing are measured, which provides an opportunity to estimate the dissipated power and condition of the bearing. Finally, accelerations are measured, which provides an opportunity to find defects of rolling elements and races, because vibrations are mainly excited by geometrical imperfections. This is explained, in short, in Pseudo-code 1. Data processing of obtained results, visualisation and alarm levers are not discussed in this article. More information about Arduino is presented in [11].

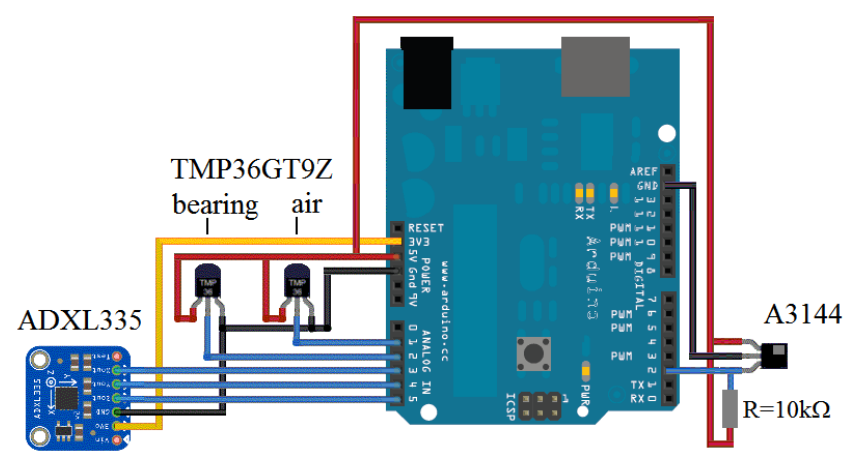

Fig. 2. Connection scheme of sensors to Arduino Uno

\section{Conclusions}

This article shows that a diagnostic system can cost about $\$ 10$ instead of $\$ 7500$; but an engineer should know about low cost sensors and programmable micro-controllers. A better system can be configured, with better sensors and more channels, but it will cost more. Moreover, machinery diagnostic is an interdisciplinary field, thus basic knowledge of sensors, electronics, signal processing and programming is necessary.

\section{References}

[1] Cempel C. Basis of Vibro-Diagnostic of Machines. WNT, Warszawa 1982.

[2] Kostek R. Simulation and analysis of vibration of rolling bearing. Key Engineering Materials, Vol. 588, 2013, p. 257-265.

[3] Kostek R., Żóltowski B. Rolling bearing defect detection and diagnostics. Vibroengineering Procedia, Vol. 6, 2015, p. 139-144.

[4] Randall R. B., Antoni J. Rolling element bearing diagnostics - A tutorial. Mechanical Systems and Signal Processing, Vol. 25, 2011, p. 485-520. 
[5] Hemmati F., Orfali W., Gadala M. S. Rolling element bearing condition monitoring using acoustic emission technique. 25th International Conference on Noise and Vibration Engineering, Leuven, Belgium, 2012.

[6] Kim W., Seo J., Hong D. Infrared thermographic inspection of ball bearing; condition monitoring for defects under dynamic loading stages. 18th World Conference on Nondestructive Testing, 2012.

[7] Leemans V., Destain M., Kilundu B., Dehombreux P. Evaluation of the performance of infrared thermography for on-line condition monitoring of rotating machines. Engineering, Vol. 3, 2011, p. 1030-1039.

[8] Cole K. D., Tarawneh C. M., Fuentes A. A., Wilson B. M., Navarro L. Thermal models of railroad wheels and bearings. International Journal of Heat and Mass Transfer, Vol. 53, 2010, p. 1636-1645.

[9] Wonderful Engineering, http://wonderfulengineering.com/10-best-vibration-meters/.

[10] https://pl.aliexpress.com/.

[11] Boxall J. Hands-On Introduction with 65 Projects. No Starch Press 2013.

\section{Appendix}

// Rotational speed. Definition of variables

int Hall_Sensor_Pin $=2$; // Define number of digital input pin int State_Hall, Old_State_Hall; // States of input pin 2 unsigned long Time, Old_Time; // Time instances of states changes of pin 2 float Rotational_Speed;

\section{// Temperature}

int Temp_Pin $1=\mathrm{A} 1 ; / /$ Analog input pin air int Temp_Pin2 = A2; // Analog input pin bearing int Voltage_Int1, Voltage_Int2; // Measured inputs float Voltage_Tm_V1, Voltage_Tm_V2; // Measured voltage in $\mathrm{mV}$ float Temp1_Air, Temp2_Bearing; // Measured temperatures in ${ }^{\circ} \mathrm{C}$

// Acceleration

int Acc Pin $3=\mathrm{A} 3$; // Analog input pin $\mathrm{X}$-axis int Acc_Pin4 = A4; // Analog input pin Y-axis int Acc_Pin5 = A5; // Analog input pin Z-axis int Voltage_Int3, Voltage_Int4, Voltage_Int5; // Measured inputs float Voltage_Acc_V3, Voltage_Acc_V4, Voltage_Acc_V5; // Measured voltage in mV float $\mathrm{Ax}, \mathrm{Ay}, \overline{\mathrm{Az}}$; // Measured acceleration in $\mathrm{g}$

void setup ()\{

$$
\text { // Instructions are done only one time }
$$

pin Mode(Hall_Sensor_Pin, INPUT); // Define digital input pin \#2

State_Hall = digital Read (Hall_Sensor_Pin); // Read state of Hall Effect sensor, pin \#2 Time $=\operatorname{micros}() ; / /$ Read initial time in $\mu \mathrm{s}$

void loop() \{

// Rotational speed

// It is closed loop

Old_State_Hall = State_Hall; // Save previous state of Hall effect sensor

State_Hall = digital Read (Hall_Sensor_Pin); // Read state of Hall Effect sensor

if $(($ Old_State_Hall $==\mathrm{HIGH}) \&($ State_Hall $==$ LOW $))\{/ /$ if shaft did one revolution Old_Time $=$ Time; $/ /$ Changes value of variable Old Time Time $=$ micros ()$; / /$ Measure time in $\mu \mathrm{s}$ Rotational_Speed $=(60.0 * 1000000.0) /($ Time-Old_Time $) ; / /$ Cal. RPM

\}

Display rotational speed

// Temperature

Voltage_Int $1=$ analogue Read $($ Temp_Pin 1$)$; // Measure input signal - Air Voltage_Tm_V1 $=($ Voltage_Int $1 / 1023.0) * 5000.0 ; / /$ Calculate voltage in $\mathrm{mV}$ 
Temp1_Air $=($ Voltage_Tm_V1 -500$) / 10 / /$ Calculate temperature of Air in ${ }^{\circ} \mathrm{C}$

Voltage_Int2 $=$ analogue Read (Temp_Pin2); // Measure input signal - Bearing Voltage Tm V2 $=($ Voltage Int $2 / 1023.0) * 5000.0 ; / /$ Calculate voltage in $\mathrm{mV}$

Temp2_Bearing $=($ Voltage_Tm_V2 -500$) / 10 / /$ Calculate temperature of Bearing in ${ }^{\circ} \mathrm{C}$ Display temperature and inform about alarm levers

// Acceleration

Voltage_Int3 = analogue Read ( Acc_Pin3); // Measure input signal - Ax Voltage_Acc_V3 $=($ Voltage_Int3/1023.0)*5000.0; // Calculate voltage in $\mathrm{mV}$ $A x=($ Voltage_Acc_V3-1500.0)/300; // Calculate acceleration $\mathrm{x}$ " in $\mathrm{g}$

Voltage_Int4 $=$ analogue Read (Acc_Pin4); // Measure input signal - Ay Voltage_Acc_V4 $=($ Voltage_Int4/1023.0 $) * 5000.0 ; / /$ Calculate voltage in $\mathrm{mV}$ $\mathrm{Ay}=($ Voltage_Acc_V4-1500.0)/300; // Calculate acceleration y" in $\mathrm{g}$

Voltage_Int5 = analogue Read (Acc_Pin5); // Measure input signal - Az Voltage_Acc_V5 $=($ Voltage_Int5/1023.0)*5000.0; // Calculate voltage in $\mathrm{mV}$ $\mathrm{Az}=($ Voltage_Acc_V5-1500.0)/300; // Calculate acceleration z" in $\mathrm{g}$ Display acceleration and inform about alarm levers 